
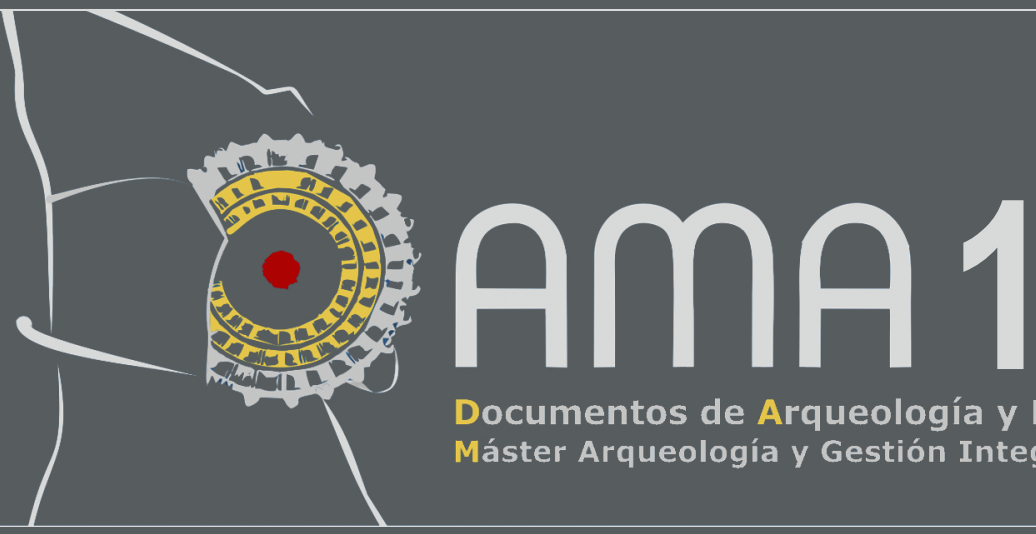

Documentos de Arqueología y Patrimonio Histórico

Máster Arqueología y Gestión Integral del Patrimonio de la Universidad de Alicante

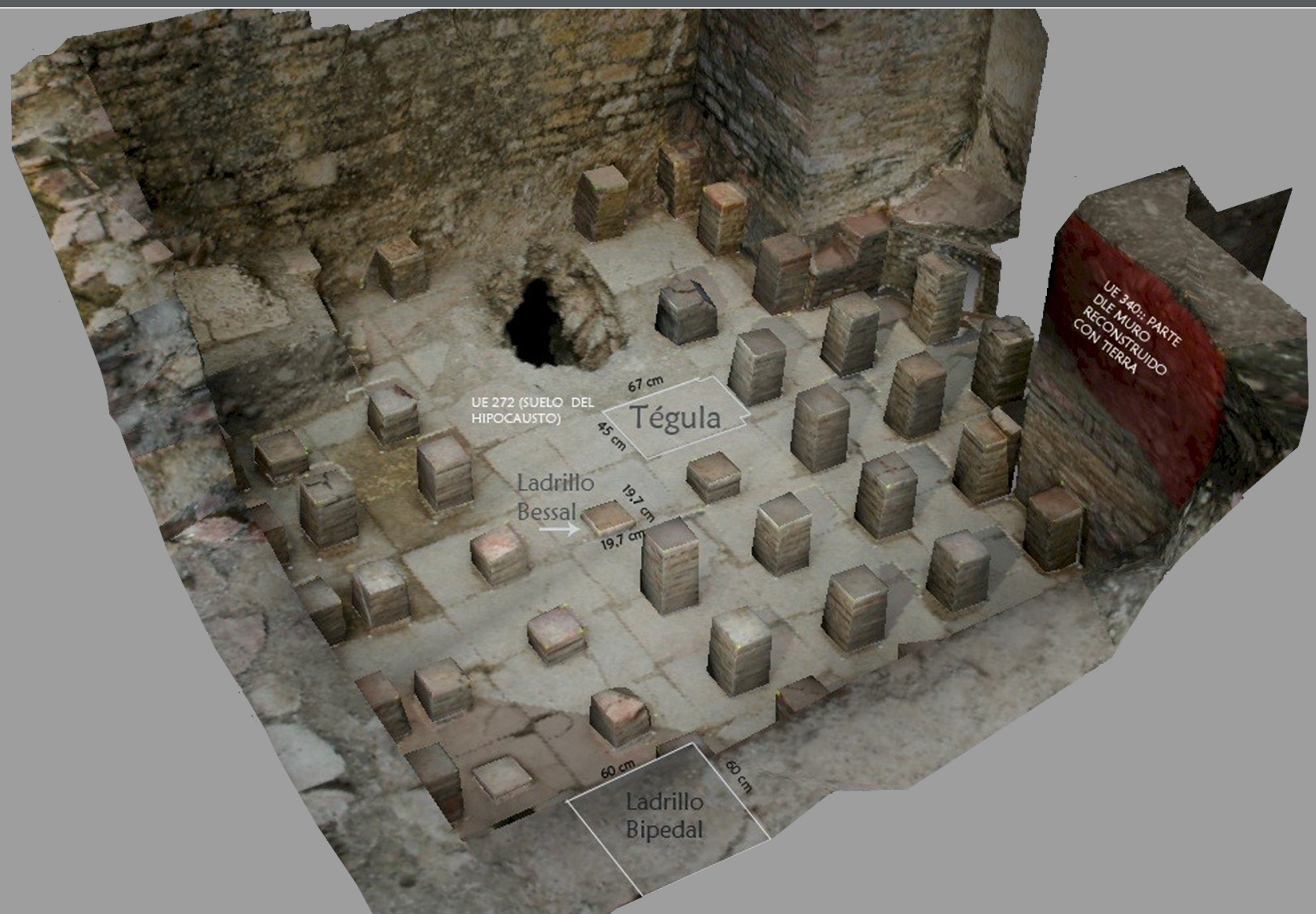

Documentos de Arqueología y Patrimonio Histórico Revista del Máster Universitario en Arqueología Profesional y Gestión integral del Patrimonio 



\section{DAMA 1}

\section{6}

DOCUMENTOS DE ARQUEOLOGÍA Y PATRIMONIO HISTÓRICO DEL MÁSTER UNIVERSITARIO EN ARQUEOLOGÍA PROFESIONAL Y GESTIÓN INTEGRAL DEL PATRIMONIO DE LA UNIVERSIDAD DE ALICANTE 


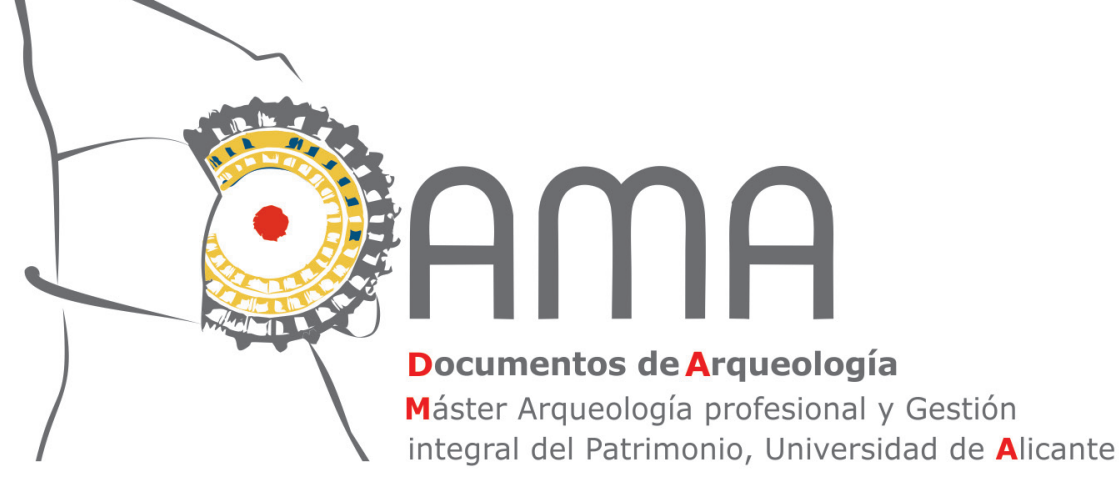

La revista electrónica DAMA. Documentos de Arqueología y Patrimonio Histórico surge como servicio para todos aquellos alumnos del Máster en Arqueología Profesional y Gestión Integral del Patrimonio de la Universidad de Alicante que se están iniciando en la investigación y cuya primera aportación a nuestra disciplina suele ser su Trabajo de Fin de Máster (TFM). Estos proyectos en muchos casos representan casi todo un curso de trabajo y esfuerzo, y con frecuencia quedan inéditos.

El objetivo de esta revista es ofrecer un medio que facilite la publicación de los resultados de sus TFM. La edición se presenta en versión digital y cuenta con su correspondiente ISSN. Se publica de forma anual en el sitio web de la Universidad de Alicante (http://web.ua.es/es/dama/) y en su repositorio (RUA). Los artículos publicados son descargables en formato PDF.

\section{Consejo de Redacción}

Directores (Coordinadores del Máster)

Carolina Doménech Belda

Fernando Prados Martínez

\section{Secretaria de Edición}

Julia Sarabia Bautista

\section{Vocales}

Los miembros de la Comisión Académica del Máster Universitario en Arqueología Profesional y Gestión del Patrimonio (http://dprha.ua.es/es/magip/comision-academica.html)

\section{Edita}

Máster Universitario en Arqueología Profesional y Gestión Integral del Patrimonio Departamento de Prehistoria, Arqueología, Historia Antigua, Filología Griega y Filología Latina

Facultad de Filosofía y Letras II

Universidad de Alicante

Ctra San Vicente del Raspeig s/n

E-03690 San Vicente del Raspeig (Alicante)

Web:http://dprha.ua.es

Teléfono: (+34) 965903663

Fax: (+34) 965903823

E-mail: revista.dama@ua.es

\section{ISSN}

$2530-2345$

\section{Portada}

Modelo fotogramétrico de un hypocaustum romano realizado por Ana Charquero 
EDITORIAL

Coordinación del máster

ENTREVISTA A SOLVEIG NORDSTRÖM: UNA MIRADA HACIA EL PASADO DE LA ESCUERA

Raúl Berenguer González ..

\section{ARQUEOLOGÍA Y MÉTODO}

EL ESTUDIO DE LOS MATERIALES CONSTRUCTIVOS DE TIERRA DEL CABEZO DEL POLOVAR (VILLENA, ALICANTE): APORTACIÓN A LAS FORMAS CONSTRUCTIVAS DE DOS PEQUEÑAS EDIFICACIONES CAMPESINAS DE LA EDAD DEL BRONCE EN EL LEVANTE PENINSULAR

María Pastor Quiles

VIVIENDAS POSTALAYÓTICAS: UNA APROXIMACIÓN A LOS ESPACIOS DOMÉSTICOS EN EL ARCHIPIÉLAGO BALEAR (550-123 ANE)

Octavio Torres Gomáriz

LAS FLOTAS DE GUARNICIÓN ROMANA EN LAS COSTAS DE HISPANIA A PARTIR DE LAS FUENTES EPIGRÁFICAS

Sergio Lledó Ramírez

UNA APROXIMACIÓN A LA RECONSTRUCCIÓN DEL PAISAJE HISTÓRICO: EL PROYECTO L'ALMISSERÀ Diana López Arroyo

NUEVAS PERSPECTIVAS PARA EL ESTUDIO ARQUEOLÓGICO DEL POBLAMIENTO RURAL MEDIEVAL EN ASPE (ALICANTE): HUERTAS Y ALQUERÍAS JUNTO AL RÍO TARAFA

Felipe Mejías López

ARQUEOLOGÍA DE LAS GUERRAS CARLISTAS

Iván Roldán Vergarachea

LA CERÁMICA DE USO ARQUITECTÓNICO EN NOVELDA: LA AZULEJERÍA DE FINALES DEL SIGLO XIX Y PRINCIPIOS DEL XX

Natalia Sala Pérez

PRÁCTICA Y USOS DE LA FOTOGRAMETRÍA DIGITAL EN ARQUEOLOGÍA

Ana $M^{a}$ Charquero Ballester.

\section{GESTIÓN Y PUESTA EN VALOR DEL PATRIMONIO}

ARQUEÓLOGOS CON DISCAPACIDAD. ARQUEOLOGÍA INCLUSIVA

Ana Samaniego Espinosa

"LES COVES DELS PESCADORS DE EL CAMPELLO": PROPUESTA DE RECUPERACIÓN, PUESTA EN VALOR Y USO PÚBLICO DE UN PATRIMONIO OLVIDADO

Ana Isabel Castro Carbonell .

LA COLONIA DE SANTA EULALIA. ESTUDIO Y PROPUESTA DE RECUPERACIÓN

Héctor de Arriba González

PROYECTO DE PUESTA EN VALOR DE LOS RESTOS DE LA GUERRA CIVIL EN LA CIUDAD DE ALICANTE

Leticia Victoria González Chouciño

ANTEPROYECTO MUSEOGRÁFICO DEL MUSEO DE HISTORIA DE SAX

Alberto Ochoa García

EL CONGRESO DE MÁSTER: UNA PROPUESTA DIDÁCTICA DEL MÁSTER DE ARQUEOLOGÍA DE LA UNIVERSIDAD DE ALICANTE

Ignasi Grau Mira, Sonia Gutiérrez Lloret, Carolina Doménech Belda, Julia Sarabia Bautista 



\title{
EL ESTUDIO DE LOS MATERIALES CONSTRUCTIVOS DE TIERRA DEL CABEZO DEL POLOVAR (VILLENA, ALICANTE): APORTACIÓN A LAS FORMAS CONSTRUCTIVAS DE DOS PEQUEÑAS EDIFICACIONES CAMPESINAS DE LA EDAD DEL BRONCE EN EL LEVANTE PENINSULAR
}

\author{
María Pastor Quiles
}

\section{RESUMEN}

En este artículo se presentan los resultados del estudio macrovisual del conjunto de elementos constructivos de barro del Cabezo del Polovar, un yacimiento de la Edad del Bronce situado en la cubeta de Villena (Alicante). Los restos proceden de dos edificaciones diferentes, situadas en lo alto de dos de las crestas de este cerro. Su estudio ha permitido conocer mejor la forma que adoptaron estas estructuras, así como algunos aspectos del proceso productivo realizado necesariamente para su construcción. En estas pequeñas ocupaciones campesinas se utilizaron recursos procedentes del entorno natural y de las actividades económicas realizadas por parte de los grupos humanos que las habitaron. Además, se abordan de manera breve las construcciones realizadas en otros poblados cercanos y de similar cronología.

Palabras clave: Prehistoria, construcción con tierra, Edad del Bronce, recursos naturales, residuos agrarios.

\section{ABSTRACT}

In this article we present the results of the macroscopic analysis of earth building remains from the Bronze Age settlement of Cabezo del Polovar, located in the Villena basin, in Alicante. These remains were found in two different archaeological constructions, located on top of two of the crests of the settlement hill. Its analysis has allowed us to have a better knowledge about how these buildings were and to know some aspects about the productive processes that had been necessarily carried out by the groups that inhabited them. In these small farmer occupations natural resources obtained in the nearest environment were used, as well as waste generated by their economic activities. Besides, we briefly discuss the way other settlements in the same area with similar chronology were built.

Key words: Prehistory, earth construction, Bronze Age, natural resources, agrarian waste. 


\section{INTRODUCCIÓN}

La tierra ha sido ampliamente utilizada como material de construcción por las sociedades del pasado desde la Prehistoria. Diferentes factores han propiciado que, en muchos casos, los restos arqueológicos de la edificación con tierra no hayan sido considerados como fuentes de información, entre los que se encuentran las dificultades de su conservación en el registro arqueológico. No obstante, su análisis específico es necesario para poder conocer mejor la forma que adoptaron las construcciones prehistóricas, así como para aproximarnos a cómo fue su proceso constructivo.

En este texto presentamos un nuevo caso de estudio, el de dos construcciones de la Edad del Bronce documentadas en el yacimiento del Cabezo del Polovar (Villena, Alicante) (Fig. 1.). El análisis de los restos arqueológicos de construcción con tierra recuperados en el mismo aporta datos sobre sus formas constructivas, complementarios a los obtenidos durante sus procesos de excavación.

Del mismo modo, permite plantear diferentes cuestiones acerca del aprovechamiento del medio natural y económico de estos grupos humanos en el marco de las tareas de edificación.

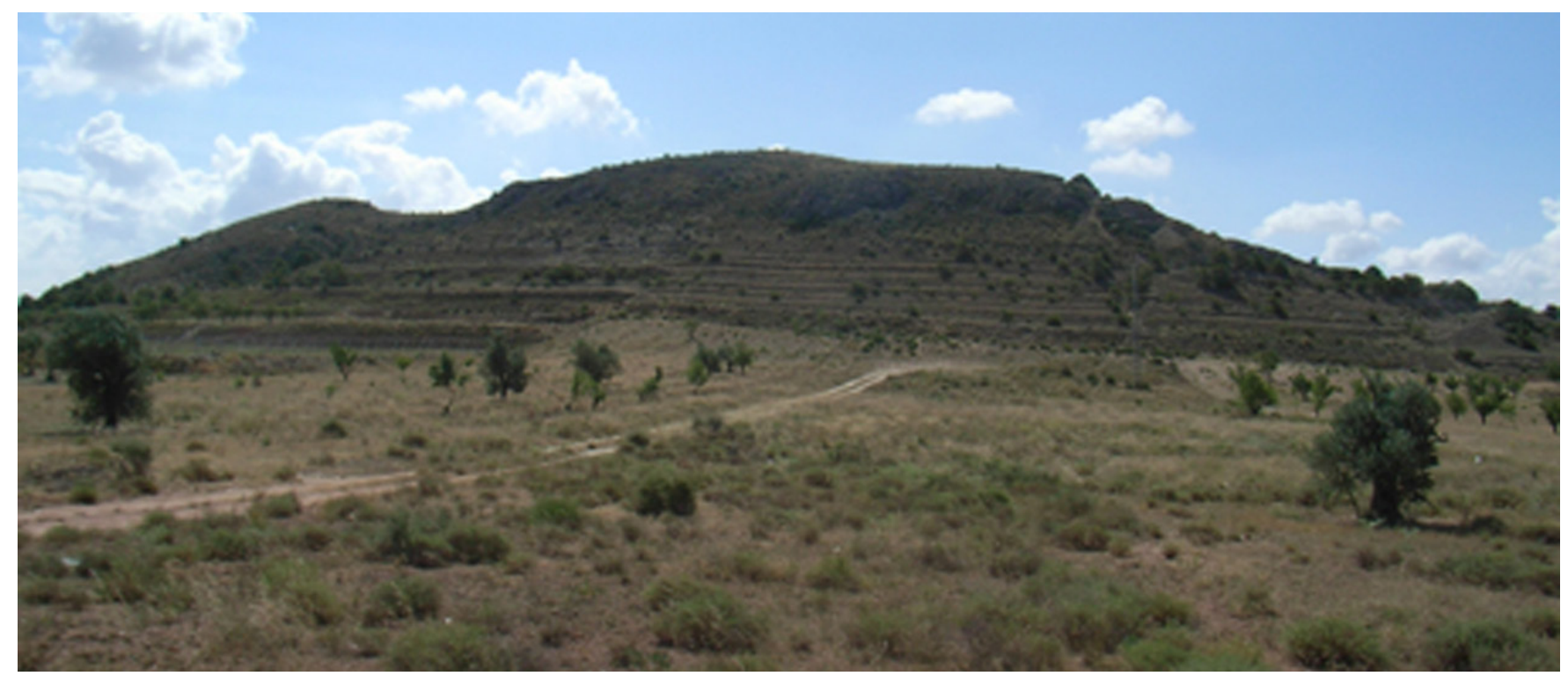

Fig. 1. Vista del Cabezo del Polovar (Jover et al., 2016, p. 42, Fig. 2).

\section{LAS ESTRUCTURAS DEL CABEZO DEL POLOVAR}

El Cabezo del Polovar es un cerro aislado, con tres crestas, ubicado en el centro de la cubeta de Villena. En él se han documentado evidencias de ocupación humana con una cronología de la Edad del Bronce, establecida entre inicios y mediados del II milenio cal BC (Jover et al., 2016). Las labores de excavación en extensión realizadas en este yacimiento tuvieron lugar en dos zonas, en la cresta occidental en el año 2012 y en la central durante las campañas de 2013 y 2014.

En la cresta occidental (Fig. 2) se pudo documentar una única construcción, reforzada por un grueso muro de aterrazamiento. Esta edificación habría estado conformada por un alzado, del que se han conservado hasta tres hiladas de piedra, y postes de madera sustentantes de la techumbre, identificados mediante sus calzos. La techumbre la habrían sostenido travesaños de madera, algunos de cuyos restos se han conservado carbonizados en el estrato de incendio, caídos sobre el suelo de la estancia. Este edificio pavimentado ha sido interpretado como una cabaña semiabierta que podría haber servido como cobertizo o lugar de refugio y almacenaje de enseres domésticos y/o alimentos. Habría sido destruida por un incendio, fechado por datación radiocarbónica por una muestra de vida 


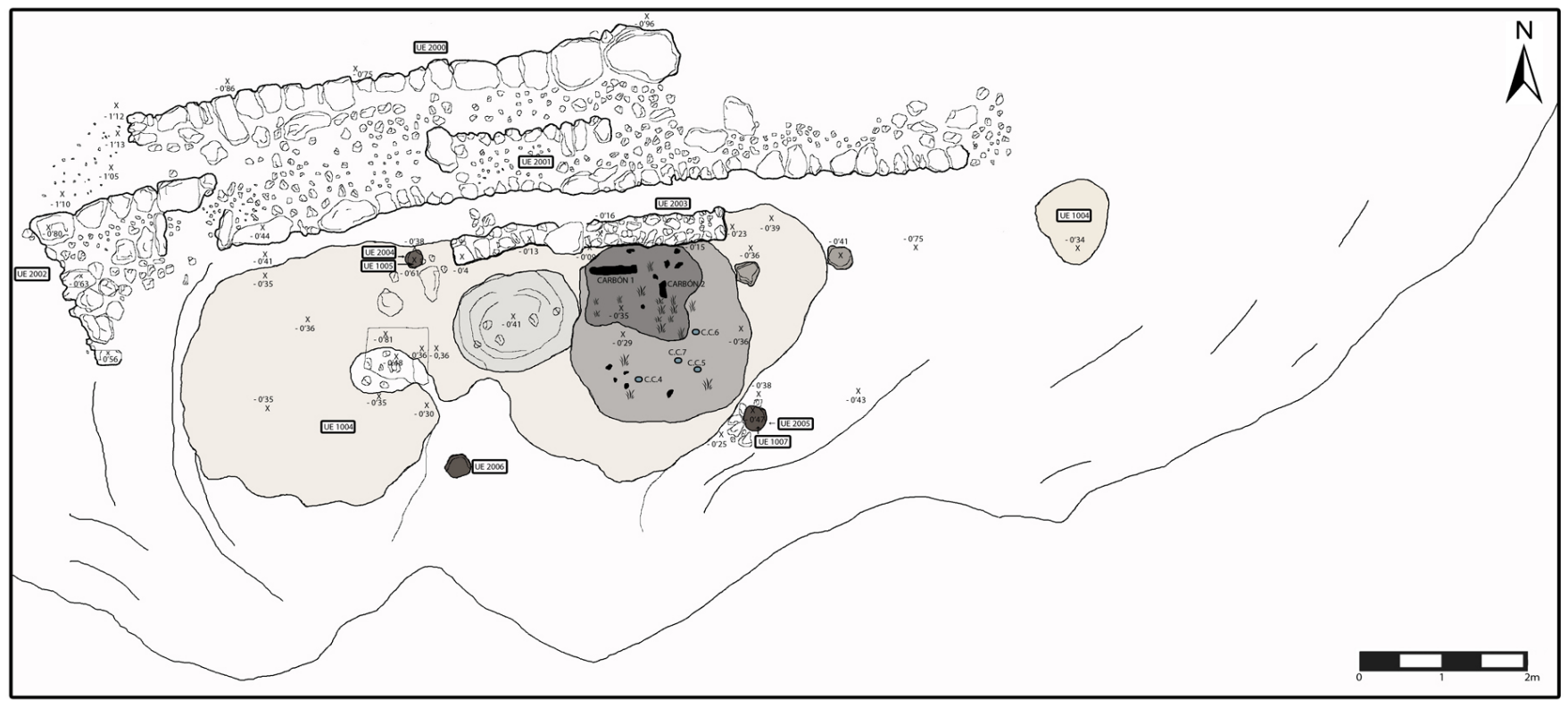

Fig. 2. Dibujo de la planta de las estructuras halladas en la cresta occidental (Jover et al., 2016, p. 51, Fig. 5).

corta hacia una fecha media de 1815 cal BC -Beta-332585: $3530 \pm 30 \mathrm{BP} ; 1940-1770 \mathrm{cal} \mathrm{BC}(2 \sigma)-^{1}$.

Durante el proceso de excavación de las unidades estratigráficas de derrumbe de la edificación se recuperaron 11 fragmentos de barro, correspondientes a la que se ha interpretado como su única fase de ocupación. Por otro lado, en la cresta central del yacimiento (Fig. 3) fueron halladas dos estancias contiguas de tamaño modestoy de planta rectangular, delimitadas por algunos tramos de muros de escasa altura, construidos con piedra caliza local. Ambas construcciones, coetáneas y con un único nivel de ocupación, también habrían sido destruidas de forma repentina por un incendio. Del mismo modo, se encuentran severamente afectadas por procesos erosivos, en especial el ambiente 1, ubicado sobre la cresta del cerro. La datación radiocarbónica de un excremento de ovicaprino hallado en el interior de un resto constructivo de tierra (Fig. 7), proporcionó una cronología de entre el 1585/1545-1436 cal

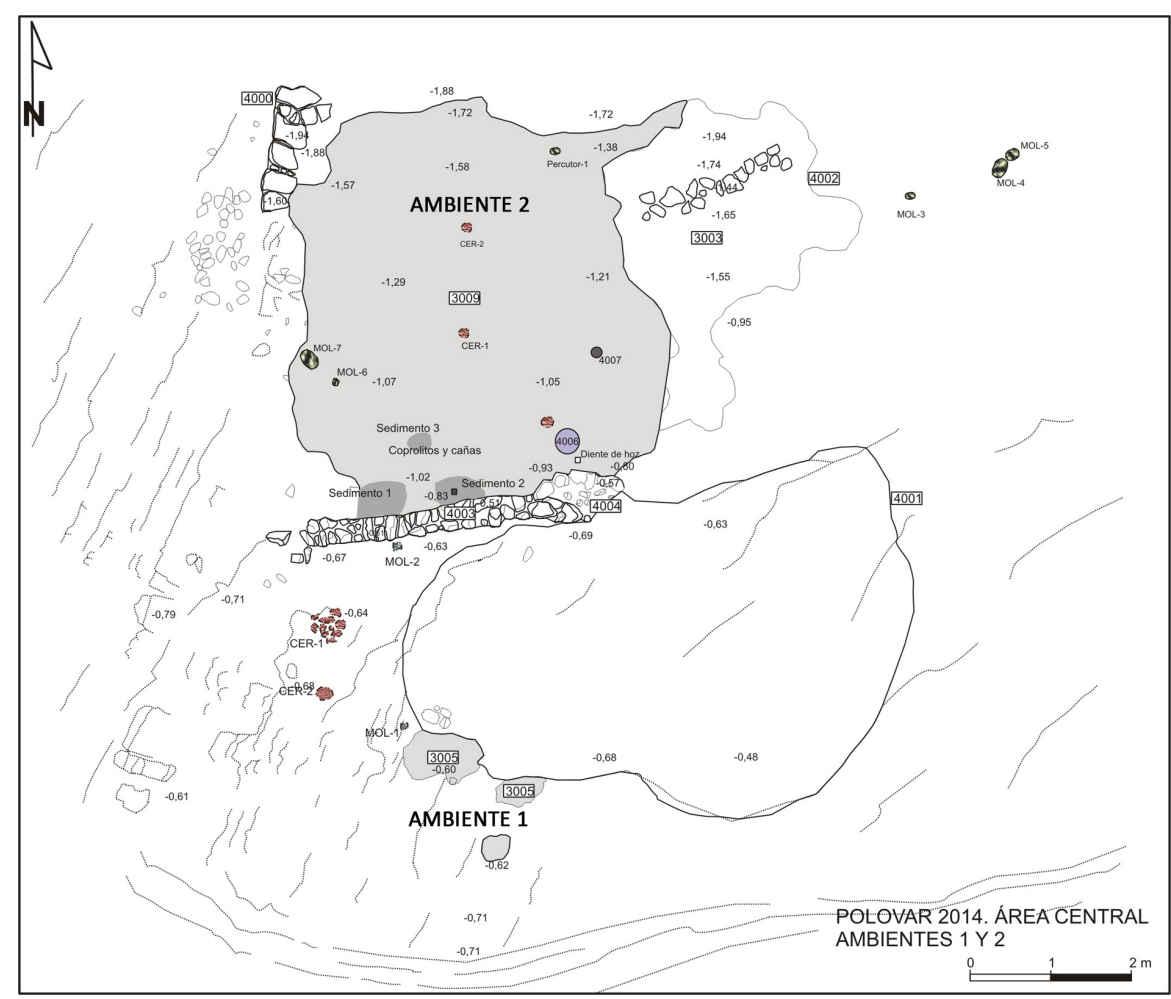

Fig. 3. Dibujo de la planta de las estructuras halladas en la cresta central (Jover et al., 2016, Fig. 11).

1 Todas las calibraciones han sido realizadas con el programa OxCal v4.2.3. (Ramsey, 2013), utilizando la curva de calibración Intcal13 (Reimer et al., 2013). 
BC -Beta-397232: $3230 \pm$ 30BP; 1605 - 1585 y 1545 - 1436 cal BC (2 o)- (Jover et al., 2016). Por lo tanto, la construcción o una actividad posterior de mantenimiento de estas estructuras de la cresta central se sitúan a mediados del II milenio cal BC. Durante la excavación del ambiente 1 se recuperaron nueve fragmentos de barro endurecido. En el ambiente 2, ubicado hacia el norte de éste y ya en la pendiente del cerro, fueron documentados un silo excavado en la roca y un calzo de poste. El silo podría haber sido empleado para contener grano, en relación a los elementos de molienda hallados en la estancia (Jover et al., 2016). Los niveles de derrumbe de la edificación estaban constituidos por barro compactado de gran dureza, y de este contexto se recuperaron 20 fragmentos.

Debido a unas determinadas condiciones de destrucción y sepultamiento y a la acción de distintos procesos postdeposicionales, la mayor parte de las evidencias del empleo constructivo de la tierra en estas edificaciones han quedado materializadas en los contextos arqueológicos en forma de estratos de tierra, que se documentaron y fotografiaron durante los procesos de excavación en el yacimiento. Afortunadamente, la acción del fuego que destruyó las estructuras ha favorecido la conservación de restos de barro, más o menos endurecidos, que nos proporcionan información sobre el empleo de la tierra en las edificaciones del Cabezo del Polovar. A continuación, se recogen los resultados del estudio de estos materiales constructivos, realizado mediante una aproximación macroscópica ${ }^{2}$.

\section{CARACTERIZACIÓN DE LOS ELEMENTOS CONSTRUCTIVOS DE BARRO DEL CABEZO DEL POLOVAR}

El conjunto de fragmentos de barro estudiados se compone de 40 restos, recuperados a lo largo de los trabajos de excavación realizados en el asentamiento. Estos materiales proceden en todos los casos de contextos arqueológicos primarios: de las unidades de incendio, derrumbe y destrucción de las construcciones, o de los niveles inferiores de uso y pavimentación. Estos elementos han sido recogidos de manera selectiva, por lo que, unido esto a la conservación diferencial de este tipo de materialidad, los restos estudiados son sólo una muestra del total de las evidencias constructivas de tierra que se habrían generado en el asentamiento.

El estudio macrovisual de estas piezas fue realizado en las instalaciones del Museo Arqueológico Municipal “José María Soler” de Villena, así como en el laboratorio de Prehistoria de la Universidad de Alicante ${ }^{3}$.

\subsection{La edificación en la cresta occidental}

Durante la excavación de los restos arqueológicos detectados en la cima de esta cresta se recogieron 11 restos de barro, correspondientes a tres unidades estratigráficas asociadas al único alzado documentado de la estancia, el muro de mampostería UE 2003. Dos de ellos proceden de la UE 1002, un estrato de coloración y composición heterogénea, con presencia de algunos restos constructivos, carbón y materiales arqueológicos, que cubre a los niveles de incendio y pavimentación. Otros dos fragmentos se corresponden con la UE 1003, estrato de coloración oscura y con abundante presencia de materia orgánica carbonizada, en el que se hallaron los restos de un textil vegetal trenzado, probablemente un cesto, que contenía semillas carbonizadas (Jover y Martínez, 2012). En último lugar, se recuperaron cinco restos de la UE 1004, un estrato compacto y alisado de coloración blanquecina, interpretado como el pavimento de esta construcción.

2 El presente artículo es una reelaboración y adaptación de uno de los apartados incluidos en nuestro Trabajo Fin de Máster "La construcción con tierra en arqueología: aproximación teórica, metodología y aplicación a la Prehistoria reciente”, del Máster en Arqueología Profesional y Gestión Integral del Patrimonio, en su curso académico $2014-2015$. Agradecemos a F.J. Jover Maestre la tutela y la revisión del mismo.

3 Agradecemos al personal del museo el habernos atendido muy amablemente durante el estudio de materiales. 

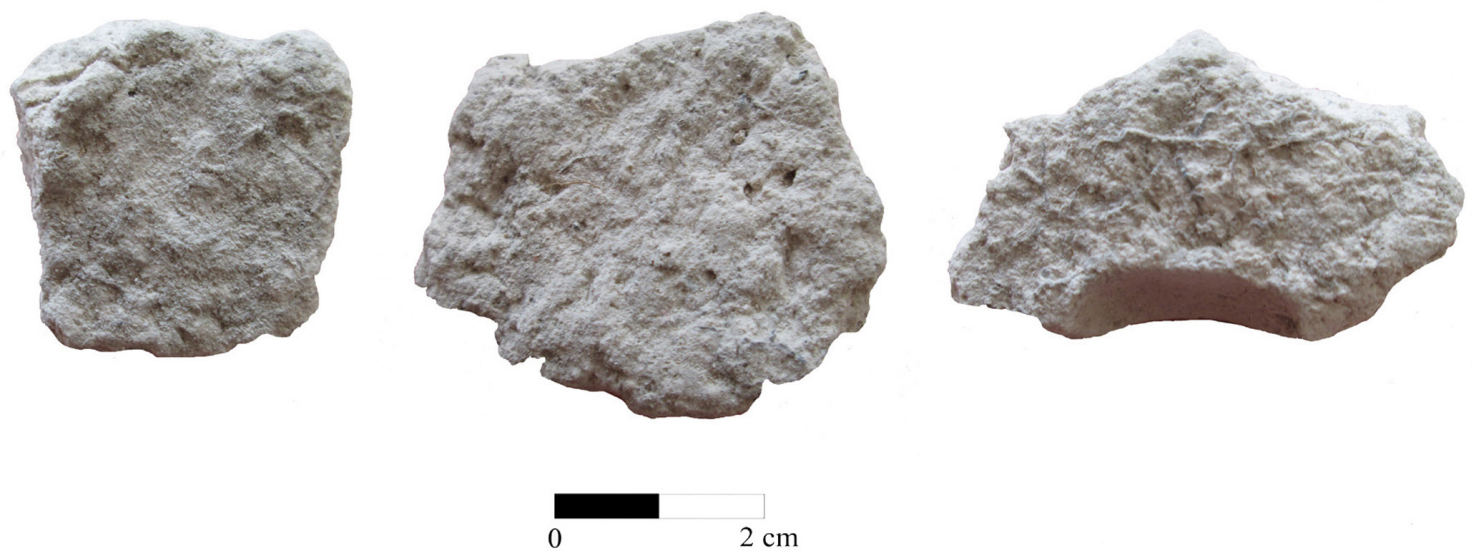

Fig. 4. Restos de pavimentación de la cabaña semiabierta de la cresta occidental (de izquierda a derecha, 1004-4, 1004-2, 1004-3).

Desde un punto de vista formal, distinguimos dos grupos. Por un lado, cinco de los restos son compactos, de composición homogénea, el mayor de ellos con unas dimensiones de 5 x 4 x $3 \mathrm{~cm}, \mathrm{y}$ pertenecen a la UE 1004 o pavimento. De ellos, la pieza 1004-1 muestra sólo una cara alisada y curva, y los otros cuatro mostrarían dos superficies lisas y paralelas. Su color blanquecino -coloración M7.5YR8/1, según el catálogo estándar Munsell- y su tacto suave parecen corresponderse con una composición a base de yeso natural, que forma parte de la composición geológica del cerro en el que se ubica el yacimiento y de la cubeta de Villena en general (Fig. 4).

En elsegundogrupo seencuentran seis restos que podemos denominar bloques, debido a su mayor tamaño -hasta $18 \times 16,5 \times 7,5 \mathrm{~cm}-$, con un aspecto distinto al de los anteriores, una coloración oscura -M10YR3/1-, grisácea -M10YR5/1- y marrón M7.5YR5/2-, y una escasa consistencia. Tres de los bloques presentan una cara regularizada o alisada (Fig. 5) y otros tres tienen dos caras alisadas y paralelas. En la composición del mortero de los bloques se observan piedras, de hasta $3,2 \mathrm{~cm}$ de largo en uno de ellos.

Si bien puede establecerse que los cinco fragmentos de la UE 1004 son restos de la

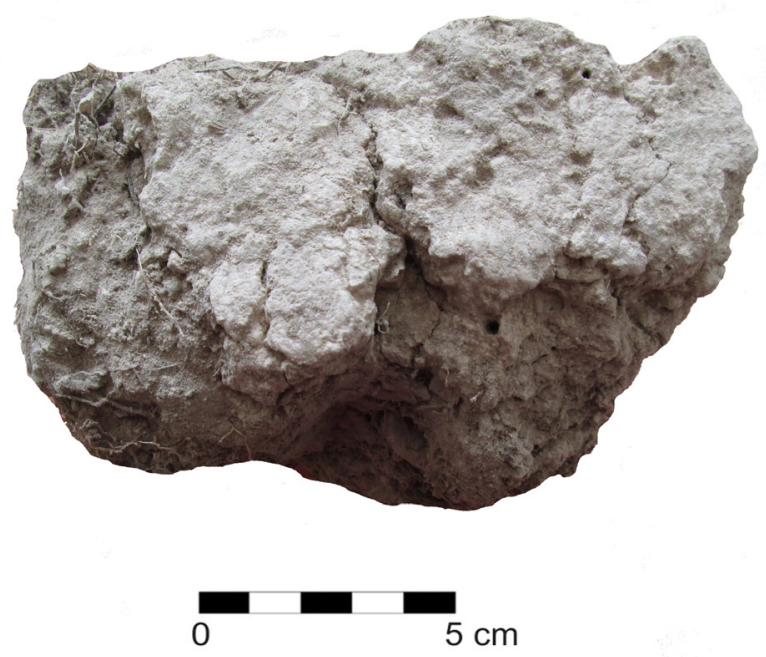

Fig. 5. Bloque constructivo de barro con superficie alisada y posible enfoscado, procedente de la cresta occidental (1003/1-1). pavimentación de la estancia, la procedencia de los bloques es difícil de determinar con exactitud. En este sentido, dado que presentan una o dos caras alisadas, parecen corresponderse con superficies de la edificación construidas mediante la técnica del amasado, o de un manteado de barro sobre elementos vegetales -bahareque-, del que no se hayan recuperado restos que conservaran improntas. En dos de estos seis casos, parece distinguirse una capa externa diferenciada, aplicada a modo de enfoscado o regularización que habría quedado expuesta a la vista.

Así, la estructura edificada en lo alto de la cresta occidental del Cabezo del Polovar contaría con un muro de piedras, al menos hasta una cierta altura. En esta estancia se han conservado diferentes calzos y agujeros de poste, así como rocas planas que pudieron utilizarse como base de otros postes 
de madera que sustentarían la techumbre, que se habría construido con largueros de pino (Jover y Martínez, 2012) y, probablemente, materia vegetal manteada con barro. De hecho, en el nivel de incendio se hallaron troncos carbonizados, que habrían contribuido a sostener la techumbre, derruida a causa del incendio. Los bloques que no presentan improntas constructivas pero sí una cara alisada con posible enfoscado pertenecerían a las partes superiores del alzado, mientras que se pueden asociar a la techumbre los bloques con improntas de elementos de madera, que se habrían manteado con barro.

\subsection{Ambiente 1 de la cresta central}

Los nueve fragmentos de barro recuperados en la campaña de excavación de 2013 proceden de dos unidades estratigráficas: la UE 3004, el nivel de incendio de este ambiente, conservado de manera muy puntual, y la UE 3005, denominación otorgada a un probable pavimento. Las dimensiones de las piezas de este conjunto alcanzan los 6-7 cm de largo, 4-5 cm de ancho y 2-3 cm de espesor en la mayoría de los fragmentos, con la excepción de un bloque de mayor tamaño, 16 x 11 x 4,5 cm, el único de ellos asociado a la UE 3005 o pavimento -pieza 3005/1-1-.

Es destacable que en una parte de los restos de este conjunto puedan observarse, al igual que en los restos de la cresta occidental, piedras de hasta $2 \mathrm{~cm}$ de largo en el interior del mortero de barro. Por otro

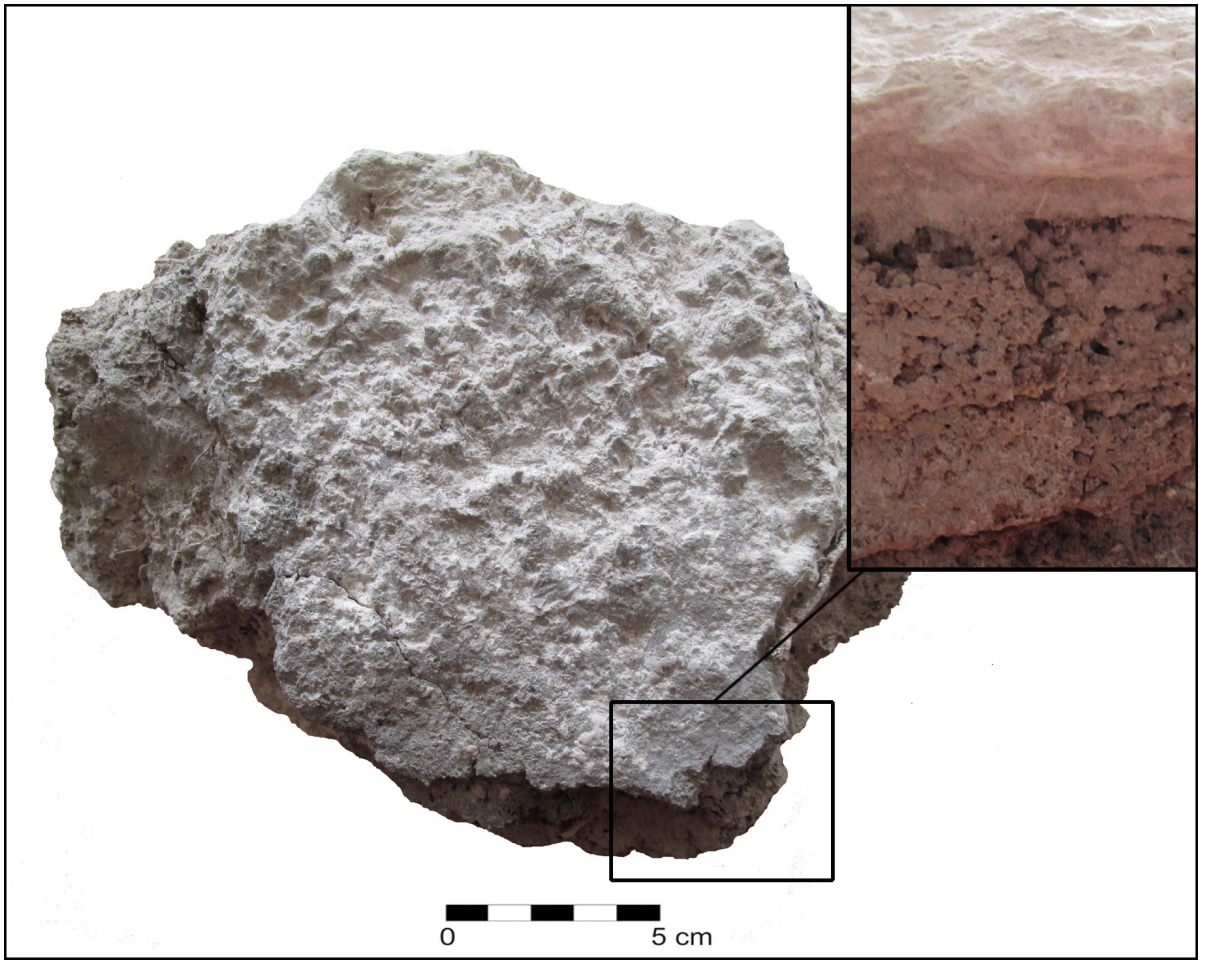

Fig. 6. Resto de la pavimentación de tierra del ambiente 1 de la cresta central, con cuatro capas superpuestas (3005/1-1). lado, algunos de los restos presentan huellas negativas de vegetales de diámetro muy reducido, de tipo tallo o paja. En los fragmentos recuperados en el ambiente 1 se ha identificado también, de manera macroscópica, la presencia de yeso natural en su composición. Los elementos constructivos del ambiente 1 presentan una coloración negruzca -M10YR3/1-, grisácea M10YR5/1- y marrón claro -M7.5YR5/2-.

En cuanto a su morfología, tres fragmentos pueden clasificarse como informes y otros dos - piezas 3004/191 y 3004/19-2- presentan una cara regularizada $\mathrm{y}$ más o menos alisada, que se correspondería con la superficie externa de una construcción. La pieza de mayor tamaño del conjunto -3005/1-1-, y la única asociada al nivel de pavimento, presenta cuatro capas superpuestas y distinguibles a simple vista, también por su diferente coloración (Fig. 6). Estas capas constituirían sucesivas preparaciones y/o pavimentaciones del suelo de la estancia. La que sería la última de ellas, de una granulometría mucho más fina y coloración blanquecina, presenta además distintas marcas en la superficie, que podrían corresponderse con residuos vegetales ya desaparecidos. 
Asimismo, otras dos piezas -3004/14-2 y 3004/14-3- presentan una superficie curva con un tratamiento alisado, a modo de borde o esquina suavizada. Estos elementos pueden interpretarse como restos de estructuras de barro, a modo de bancos, poyetes o cubetas de almacenaje, según el caso, aunque es difícil aproximarse a su naturaleza concreta. En este ambiente se hallaron restos cerámicos y de molienda, materiales relacionados con la producción y el consumo de alimentos, por lo que es muy posible que la construcción que se situó en la cima de la cresta central del Cabezo del Polovar contara con equipamiento doméstico modesto elaborado con tierra, relacionado con estas actividades cotidianas. En este sentido, otra de las piezas -3004/19-4-puede interpretarse como un resto de recipiente o vaso de barro, de factura tosca y paredes gruesas, que parece contar con una forma de tipo lengüeta en su cara externa, que habría podido funcionar a modo de asidero.

Teniendo en cuenta estas evidencias, podemos afirmar que la tierra se habría empleado de distintas maneras en la construcción y el acondicionamiento de esta estructura, probablemente destinada al hábitat y a distintas actividades productivas. Además de haber contribuido a la conformación de sus alzados, techumbre y pavimentación, la tierra se habría empleado para moldear algún tipo de estructura de equipamiento doméstico. En este enclave, la tierra cruda se empleó también para fabricar, al menos, un recipiente mueble o vaso de barro.

\subsection{Ambiente 2 de la cresta central}

De un total de 20 fragmentos procedentes de la campaña de excavación de 2014, dos de ellos proceden de la UE 3008, el nivel de incendio del ambiente 2 y, el resto, de la UE 3007, el nivel de derrumbe de esta misma estancia y que cubre al anterior, compuesto por numerosas piedras y sedimento compactado y arcilloso (Jover et al., 2016). Los fragmentos presentan un tamaño muy diverso, desde 3 hasta 28,5 cm de largo, alcanzando excepcionalmente los $10 \mathrm{~cm}$ de grosor, en el caso de la pieza $3007 / 27-1$.

Estableciendo una clasificación por formas, siete de los fragmentos presentan una cara regularizada. Otros cinco son fragmentos con numerosas huellas negativas de tallos o paja, tres piezas pueden clasificarse como informes y dos presentan improntas de ramas. Finalmente, otros dos restos constructivos muestran dos caras alisadas y paralelas, y el último de ellos muestra la impronta de un tejido vegetal trenzado - 3007/27-4-.

Varios de los fragmentos procedentes del ambiente 2 presentan manchas de color blanco que han sido interpretadas, como en el caso de las otras estancias del Cabezo del Polovar, como resultado de la presencia de yeso natural en el mortero. Seis de los fragmentos muestran nuevamente piedras, de hasta 1,3 centímetros de largo. La coloración de las piezas es muy similar a la de las recuperadas en los otros dos ambientes, presentando tonos casi negros -M10YR3/1-, gris oscuro -M10YR5/1- y marrón claro -M7.5YR5/2-.

En algunos fragmentos se aprecian restos de carbón, que se relacionarían con la presencia de materia vegetal en la mezcla. De hecho, cerca de la mitad de los fragmentos recuperados en el ambiente 2 presentan improntas vegetales de tipo tallo o paja en su interior y superficies.

En el fragmento 3007/27-5, muy disgregable y de color negruzco (Fig. 7), se han podido identificar cuatro excrementos de ovicaprinos, integrados en el mortero y conservados gracias a su estado de carbonización. Asimismo, en otras dos piezas, procedentes también de los niveles de derrumbe, se aprecian huellas esféricas que podrían corresponderse con la presencia de otros ejemplares similares, pero éstos no se han conservado y su morfología también podría responder a la presencia de otros elementos esféricos, como guijarros desprendidos. 


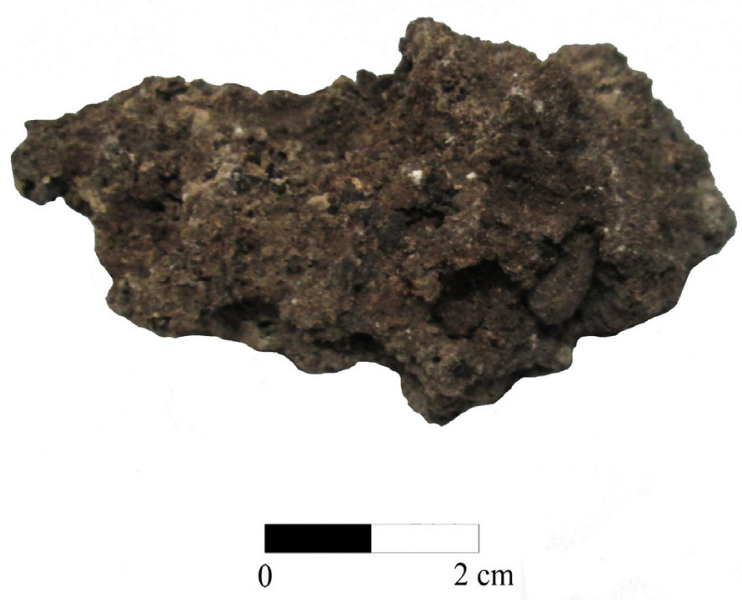

Fig. 7. Resto constructivo que contenía ejemplares carbonizados de estiércol de ovicáprido, recuperado en el ambiente 2.

vegetales de tipo tallo o paja. Por otra parte, la pieza 3007/27-4, un bloque de forma rectangular con una impronta de textil vegetal trenzado en una de sus caras, muestra también una impronta de caña de $3 \mathrm{~cm}$ de longitud en uno de los laterales. En ambos casos, las improntas se encuentran aisladas, sin otras improntas contiguas que permitan evidenciar un entramado continuo elaborado con este material. En este sentido, en el nivel de incendio asociado a esta estancia se recuperaron fragmentos de caña y carrizo carbonizados (Fig. 8), que pudieron haberse empleado como materiales constructivos.
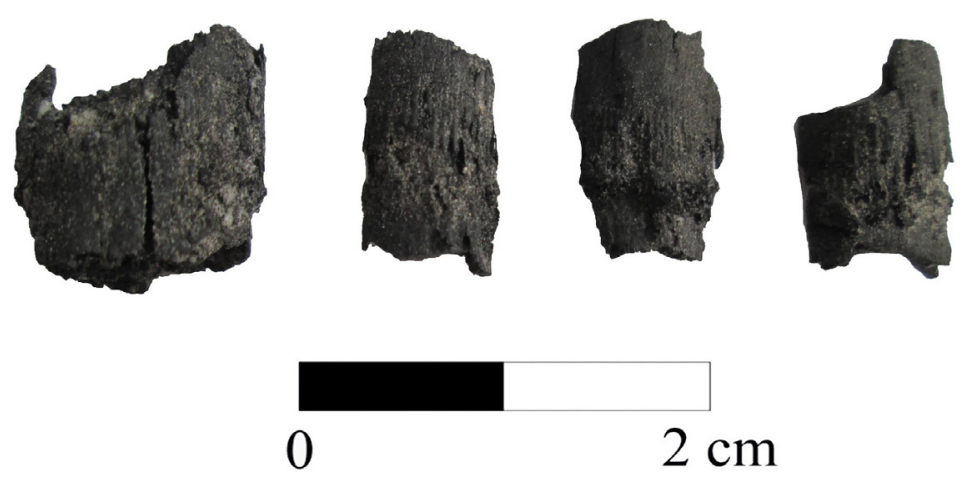

\section{$2 \mathrm{~cm}$}

Fig. 8. Restos carbonizados de caña y carrizo, recuperados en el ambiente 2, que pudieron haber pertenecido a alguna solución constructiva en esta estancia.

consistencia similares, muestra también una impronta de
En una parte de los restos del ambiente 2 se distinguen improntas de hojas o tallos de caña o carrizo, en las que son visibles las estrías verticales que los recorrieron. Estas evidencias apuntan a un posible aprovechamiento de esta planta en el interior del mortero, junto con otros elementos vegetales.

No obstante, en otros dos casos hallamos dos improntas respectivas de caña y de carrizo, con una significativa longitud conservada, que sí apuntan al empleo de estas plantas en la construcción a nivel estructural, manteadas con barro. El resto 3007/27-16 muestra el orificio dejado por un carrizo completo, una impronta de $360^{\circ}$ a lo largo de $8 \mathrm{~cm}$ y junto a impresiones 
En relación con esto, hemos mencionado más arriba que durante la excavación en la cresta occidental del yacimiento en el año 2012 se hallaron restos de textil vegetal trenzado. En el caso del fragmento del ambiente 2, si bien la impronta pudo producirse al contacto de la estera con el barro derruido durante los procesos de combustión derivados del incendio, consideramos que es probable que el textil vegetal se hubiera empleado junto a la tierra en la construcción del edificio. Podría haberse dispuesto, tanto en la techumbre, como

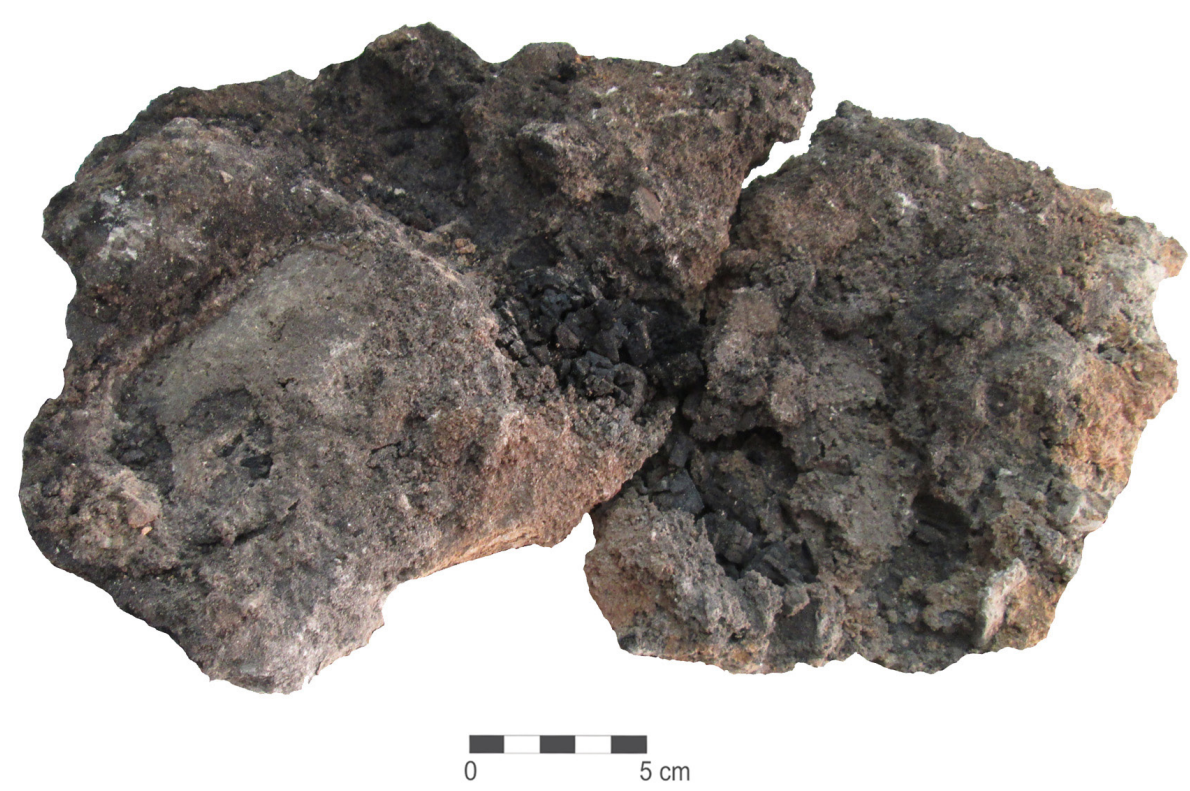

Fig. 9. Bloque de barro con impronta de rama y restos carbonizados de la misma, antes de su limpieza (3007/27-1). formando parte del cerramiento de los alzados, dado que esta misma pieza presenta una impronta constructiva de caña en uno de los laterales.

En cuanto al empleo de tejidos vegetales como material constructivo, en el cercano yacimiento de Terlinques (Villena, Alicante), se habría empleado esparto picado entre los travesaños de la techumbre del edificio 1, de la fase I (Jover y López, 2013, p. 158) (Fig. 10b). Por otra parte, son diversos los ejemplos etnográficos y etnoarqueológicos que ilustran el uso de los textiles vegetales con diferentes funciones constructivas. El empleo de las esteras de esparto, en combinación con la tierra, para la construcción de techumbres, se conoce por paralelos etnográficos en países como Siria (Aurenche, 1977, p. 124) o Pakistán (Guidoni, 1977, p. 11) (Fig. 10c). Las esteras de esparto también se dispusieron a modo de capa entre las hileras de adobe de zigurats del III milenio cal BC en el actual Irak (Aurenche, 1977, p. 124) (Fig. 10d). En este último caso, las esteras vegetales pueden estar destinadas a regular la horizontalidad de las hileras de adobe. No obstante, las fibras vegetales o animales, como diferentes plantas, tela, lana o crines, introducidas en el interior de techumbres, alzados o forjados de segundos pisos, pueden actuar como ligantes, aislantes o introducirse en el entrevigado para contribuir a sostener el manteado de barro.

Como en el caso de las estancias anteriores, a partir de la interpretación de estas evidencias siempre considerando que los fragmentos recuperados son escasos y que los restos arqueológicos del ambiente 2 han sido alterados considerablemente por distintos procesos deposicionales y postdeposicionales-, podemos formular una aportación al modo en que pudo construirse esta estancia. Para la edificación de la techumbre del ambiente 2 se habría empleado materia vegetal de distinta naturaleza -tanto troncos y ramas como algunas cañas-, manteada con barro. Pudieron utilizarse piedras que contribuyeran a sujetar la techumbre, así como esparto trenzado en la elaboración de alguna de sus partes, aunque la citada estera también podría haber pertenecido a la parte alta de un alzado.

La excavación del ambiente 2 ha permitido establecer la presencia de un poste de madera ubicado hacia la mitad de esta estancia, a 1,5 m hacia el norte del muro que lo separa del ambiente 1, que contribuiría a sostener esta techumbre. En los alzados se empleó la mampostería de piedra, al menos 

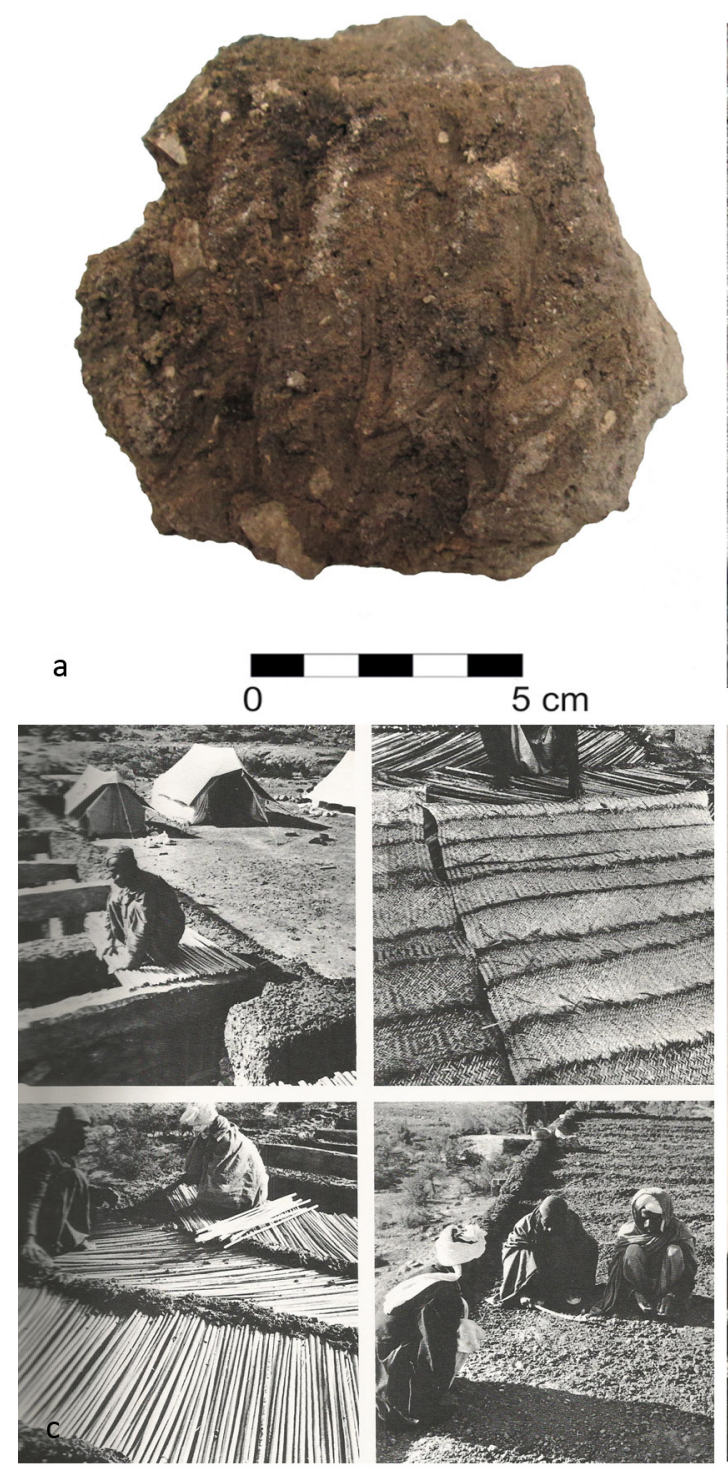
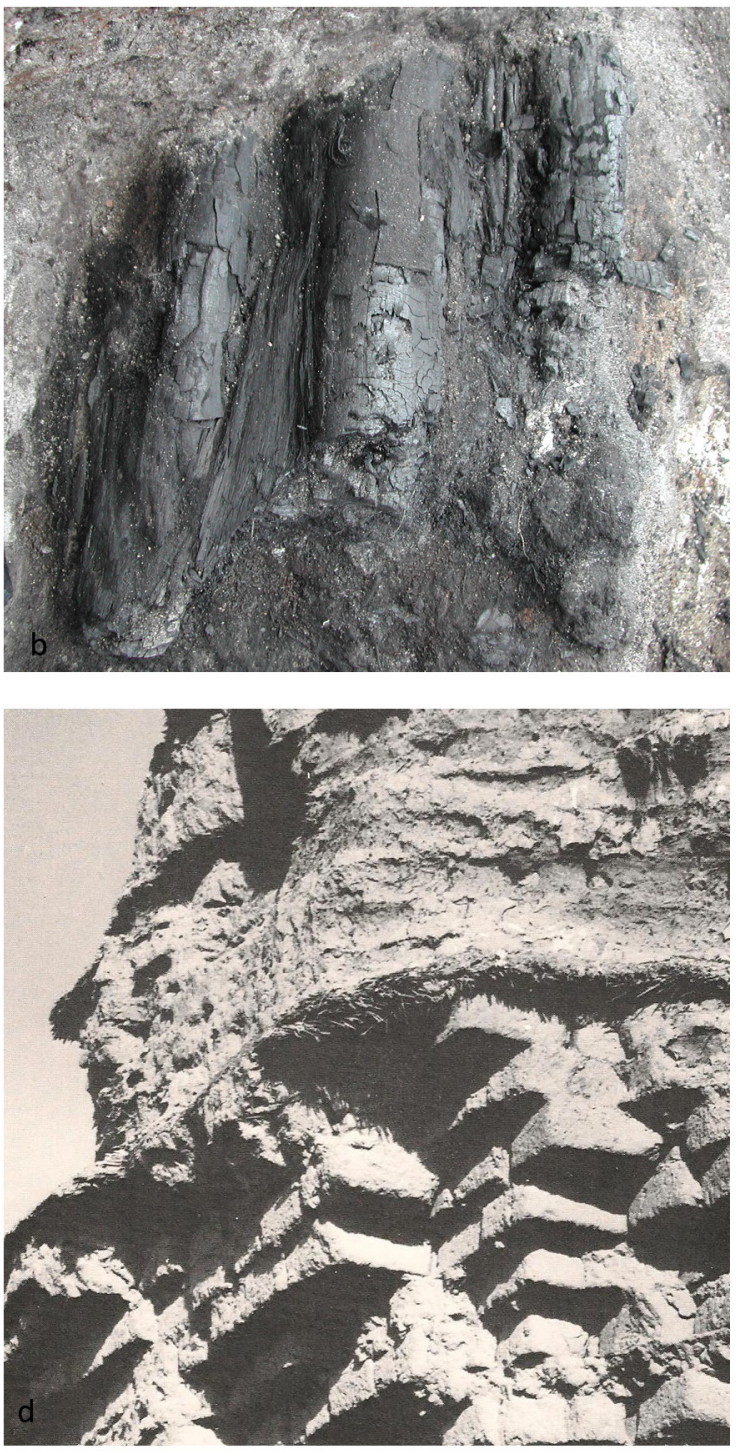

Fig. 10. Ejemplos del uso constructivo de tejidos vegetales. a. Impronta de tejido vegetal trenzado sobre un fragmento de barro del Cabezo del Polovar (3007/27-4). b. Restos de esparto hallados entre los troncos de la techumbre del edificio 1 de Terlinques (Jover y López, 2013, p. 158). c. Construcción de una techumbre con varas, esteras y barro en Pakistán (Guidoni, 1977, p. 11). d. Empleo de esteras vegetales entre hiladas de adobe de un muro del zigurat de Aqar Qouf, Irak, III milenio cal BC (Aurenche, 1977, $p$. 124, Fig. 328).

hasta una cierta altura, pero también podemos plantear el uso del barro en solitario en las partes más elevadas del edificio, teniendo en cuenta la considerable cantidad de este material que, en estado compactado y bastante homogéneo, constituía los niveles de derrumbe de la estancia. La ausencia de abundantes improntas vegetales de ramas, varas, cañas o carrizo también apunta al uso de la técnica constructiva del amasado en los alzados. Los restos con caras alisadas podrían pertenecer a la cara interna de los alzados. En la elaboración del mortero se habrían incluido residuos de la producción de cereal, como la paja, a modo de estabilizante de la mezcla. Para este mismo fin parece haber sido aprovechado el estiércol de ovicaprinos.

La pavimentación del suelo del ambiente 2 se habría preparado con capas de tierra, de las que contamos con tres restos. Ya que la textura de la tierra que compone estos fragmentos es más fina que la que muestran otros restos no asociados a la pavimentación, podemos plantear que el mortero 
empleado para el acondicionamiento del suelo de la estancia fuera fruto de un proceso de elaboración diferente, en el que la tierra sí se hubiera depurado en mayor medida. De igual manera parece haber ocurrido en la construcción documentada en la cresta occidental, dado que las características que presentan los restos de pavimento en ambas crestas son similares desde una aproximación a los mismos a escala macroscópica.

\section{LA AUTOCONSTRUCCIÓN EN EL CABEZO DEL POLOVAR: APROVECHAMIENTO Y TRANSFORMACIÓN DE RECURSOS NATURALES Y AGRARIOS}

En las estructuras documentadas en las dos ocupaciones prehistóricas de ambas crestas del yacimiento del Cabezo del Polovar, la tierra se habría empleado como material constructivo de manera similar, en combinación con otros recursos presentes en la naturaleza, como la piedra, la madera y los elementos vegetales. En ambas edificaciones, no contemporáneas, han podido identificarse las técnicas constructivas del amasado y el bahareque. El barro se habría empleado en las pavimentaciones, en buena parte de los alzados -probablemente aplicado mediante el amasado de barro como continuación a los muros bajos de piedra-y en la construcción de las techumbres, asociado a una mezcla de materias vegetales, ramas y al empleo de postes y vigas sustentantes de madera. El empleo de estas materias primas de origen natural se ha identificado ampliamente en la mayoría de los poblados de la Prehistoria reciente del Levante peninsular. No obstante, éstas no fueron las únicas materias primas empleadas en la edificación. Los residuos de las actividades agrícolas y ganaderas, la base económica de estos grupos campesinos de la Edad del Bronce, también habrían sido integrados en los procesos constructivos. Por otro lado, tan solo en el ambiente 1 se han recuperado algunos restos de barro que se corresponderían con estructuras de actividad o de acondicionamiento interno, así como con un elemento mueble elaborado con este material.

La construcción de ambas edificaciones, ubicadas en lo alto de las dos crestas excavadas en este cabezo, habría sido llevada a cabo por miembros del grupo que, una vez finalizados los procesos de edificación, habitó estas estructuras hasta su destrucción, motivada por un incendio. Para conformar ambas construcciones se utilizaron recursos naturales disponibles en el entorno cercano, transformados en materiales de construcción. La madera y la piedra hubieron de seleccionarse, prepararse, transportarse y ponerse en obra mediante unos determinados conocimientos prácticos y técnicos, obtenidos de la experiencia acumulada y transmitidos de generación en generación. Lo mismo ocurre con la tierra empleada para construir que, desde el momento en que es introducida en el proceso de producción de las edificaciones, pasa de ser sedimento natural a constituir un producto antropizado, elaborado o manufacturado con unos determinados fines. Con madera y materia vegetal se elaboraron estructuras sustentantes de la techumbre y el cerramiento de la misma, unida al manteado de barro. La piedra, además de en los muros, se utilizó como base y calzo para los postes en la cresta occidental. Además, es posible que se emplearan piedras en la techumbre, para contribuir a su sujeción, tal y como puede deducirse de la impronta plana hallada en uno de los fragmentos del ambiente 2.

Durante esta preparación de los morteros se lleva a cabo su estabilización, mediante el añadido de otras materias a la tierra para su mejor comportamiento constructivo, principalmente paja $u$ otras fibras vegetales, como en el caso que nos ocupa. En el Cabezo del Polovar el barro se habría estabilizado con materia vegetal -tallos y paja de cereal-, pudiéndose plantear también la posibilidad del empleo de excrementos de ovicaprinos para este fin. La tierra que compone el mortero presenta piedras de considerable tamaño, por lo que no se habría abordado la tarea de retirarlas a la hora de elaborarlo, un rasgo común entre los materiales de construcción recuperados en los tres ambientes. Entendemos que la presencia de piedras en la tierra utilizada para construir es de origen natural, a pesar de que está documentado el empleo de guijarros como elementos estabilizantes añadidos a la tierra en técnicas constructivas como la de la tapia valenciana (Mileto et al., 2012). 
Con los datos obtenidos, las pavimentaciones de la estancia de la cresta occidental y del ambiente 2 de la cresta central podrían haberse elaborado de manera diferente al resto del mortero empleado, al utilizarse una tierra de granulometría más depurada, homogénea y sin gravas. Además, en los restos se ha identificado la presencia de yeso natural, de forma mayoritaria en los que pertenecen a pavimentaciones. En estos casos, no podemos descartar que el yeso natural, que forma parte de la geología del cabezo, se incluyera intencionadamente en la pavimentación de los suelos. Aunque no hubiera sido sometido a procesos pirotecnológicos, podría haberse preparado manualmente e introducido en el mortero con fines estabilizantes. Por su parte, algunas de las piezas, identificadas como restos de alzados, presentan capas diferenciadas en sus caras exteriores, identificadas como enfoscados. El posible uso del yeso natural en estos revestimientos, de coloración blanquecina en algunos casos, podría ser identificado mediante la realización de análisis microscópicos con técnicas instrumentales.

El estudio de elementos constructivos de tierra no sólo proporciona datos sobre la propia tierra como material constructivo, sino que también informa de otros elementos de naturaleza orgánica que conformaron la edificación pero que no se han conservado, como los elementos vegetales o las cuerdas. Gracias a las improntas negativas conservadas en las piezas, se ha documentado el empleo de la caña y el carrizo, aunque con una presencia menor. A partir de las evidencias disponibles, inferimos que estos materiales no habrían tenido un papel destacable en estas pequeñas edificaciones campesinas, pero sí habrían estado presentes como elementos constructivos y posiblemente también como estabilizantes, aprovechándose sus hojas y tallos.

Por su parte, la paja y otros residuos generados en el cultivo de cereales fueron empleados en la elaboración de los morteros durante sus procesos de estabilización. Del mismo modo, parece probable que los excrementos del ganado ovicaprino también se hubieran utilizado con estos fines en el Cabezo del Polovar, como ha sido identificado en el ambiente 2. El estiércol del ganado, junto con las fibras vegetales que contiene, es un estabilizante muy utilizado en diferentes regiones del mundo, como ocurre extensamente en el continente africano (Baloi, 2001; Oluwole, 2005; entre otros).

Por último, otro producto generado por el grupo humano que habitó esas estructuras pudo haber sido utilizado para su edificación: el textil vegetal o estera elaborada con fibras trenzadas. Por la morfología del fragmento en el que se ha identificado el resto con la impronta de tejido vegetal que cuenta con una impronta constructiva-, consideramos que el textil podría haberse encontrado integrado en la propia edificación, empleándose con usos constructivos.

\section{CONTEXTUALIZACIÓN DE LOS RESULTADOS}

Las construcciones documentadas en el Cabezo del Polovar se enmarcan necesariamente en el conjunto de ocupaciones humanas conocidas para la Edad del Bronce en el territorio del Levante peninsular. En ellas, las técnicas empleadas parecen haber tenido como denominador común a la tierra como un importante material constructivo en la conformación de los lugares de hábitat y actividad. En el ámbito social argárico, el estudio de las estructuras de hábitat ha incluido en diferentes casos el análisis de los elementos constructivos de tierra. Esto ha permitido visibilizar el empleo extendido de la técnica del bahareque de cañas y ramas, manteadas con barro, en distintos asentamientos. Es el caso de Castellón Alto (Galera, Granada) (Contreras, 2009, p. 52), Peñalosa (Baños de la Encina, Jaén) (Rivera, 2007, p. 16) o Cabezo Pardo (San Isidro/Granja de Rocamora, Alicante) (Pastor, 2014). En el Rincón de Almendricos (Lorca, Murcia), ya se identificó el empleo de residuos de la actividad agrícola como elemento estabilizante en los morteros, mediante el estudio de sus fragmentos constructivos (Ayala et al., 1989). 
En poblados de la Edad del Bronce situados fuera del territorio argárico, como en la Lloma de Betxí (Paterna, Valencia), también se ha abordado el empleo de la tierra en la edificación, documentándose construcciones de bahareque que también habrían estado enlucidas (De Pedro, 1990; 1998).

Respecto al territorio circundante más inmediato, cercano al Cabezo del Polovar se encuentra el poblado de la Edad del Bronce de Terlinques (Villena, Alicante) (Jover et al., 2001; Machado et al., 2008; 2009; Jover y López, 2009), con una cronología coetánea a la establecida para la construcción hallada en la cresta occidental del Cabezo del Polovar. En el edificio I de Terlinques, perteneciente a la fase I del asentamiento y abandonado en torno al $1950 \mathrm{cal} \mathrm{BC} \mathrm{(Jover} \mathrm{et} \mathrm{al.,} \mathrm{2014),} \mathrm{la} \mathrm{piedra} \mathrm{de} \mathrm{los} \mathrm{muros}$ de doble paramento se trabó con tierra, utilizada también para revestirlos. En las pavimentaciones, se identificó el empleo del yeso (Machado et al., 2009), como en el caso del Cabezo del Polovar. La techumbre, realizada con diferentes materias vegetales manteadas con barro, estaba sustentada por vigas de pino, atadas con cuerdas de esparto $y$, a modo de cama entre los travesaños, se habría utilizado esparto picado. En Terlinques fueron documentadas variadas estructuras domésticas fabricadas con tierra, como bancos, hogares, tabiques internos y cubetas para el almacenaje.

Del mismo modo, en el poblado de gran entidad de Cabezo Redondo (Villena, Alicante), muy próximo al cerro de Polovar y fechado en el Bronce Tardío, hacia mediados del II milenio cal BC (Hernández Pérez, 2001, p. 210), destaca el amplio uso de la tierra en la construcción doméstica, observable en distintas evidencias materiales muy bien conservadas. Sus construcciones emplean la piedra en los alzados, y se utilizaron postes de madera con profundos calzos de piedra para sustentar las vigas de la techumbre. La tierra se habría utilizado trabando la piedra de los alzados, en la parte superior de algunos muros y en los enlucidos, manteando materia vegetal y madera en las techumbres de tendencia plana, además de en las pavimentaciones (Hernández Pérez, 2012, p. 118, 121). En el departamento XXVII se han documentado huellas de esteras de esparto trenzado sobre un banco de barro (Hernández Pérez et al., 2014, p. 217). Por su parte, las excavaciones realizadas por Soler García (1987) documentaron fragmentos con improntas de caña y de tejido vegetal trenzado (Soler, 1987, p. 326, Fig. 54) y restos de enlucidos, así como diferentes elementos muebles (Soler, 1987, p. 111, 327, Fig. 55) e inmuebles, como poyetes (Soler, 1987, p. 76). En este yacimiento también se empleó yeso en estado natural en las labores de edificación (Fumanal et al., 1996, p. 19).

La tierra y la madera se emplearon de forma similar en otros poblados de la Edad del Bronce de la cubeta de Villena, como en el asentamiento de reducidas dimensiones de Los Pedruscales (García, 2004, p. 349), o en Las Peñicas (Hernández Alcaraz et al., 2004, p. 360-361).

En definitiva, las edificaciones documentadas en el Cabezo del Polovar (Jover y Martínez, 2012; Jover et al., 2016) ejemplifican la construcción de lugares destinados a desarrollar actividades concretas, por parte de grupos campesinos asentados en el territorio de la cubeta de Villena. Tanto la estructura destinada al refugio y al almacenaje a pequeña escala de la cresta occidental, como la edificación de dos ambientes de la cresta central, que habría funcionado como lugar de hábitat y donde realizar distintas actividades destinadas a la supervivencia, se construyeron seleccionando y manufacturando materias disponibles en el entorno del grupo.

La recuperación y el estudio de restos constructivos de tierra han permitido aproximarnos con un mayor volumen de datos a las formas constructivas que se produjeron en este enclave y a sus modos de construcción. Esto ha sido posible, además, gracias el hecho de que esta materialidad arqueológica contara con información contextual, procediendo además de deposiciones primarias. La recogida y el análisis de este tipo de materiales en los procesos de excavación, preferentemente en extensión, permitirá seguir desarrollando la investigación sobre las actividades constructivas y los lugares de hábitat en la Prehistoria reciente y abordar nuevas cuestiones que en el futuro puedan plantearse. 
Aurenche, 0. (1977). Dictionnaire illustré multilingue de l'architecture du Proche Orient Ancien, Collection de la Maison de L’Orient Méditerranéen Ancien 3, Lyon.

Ayala Juan, M. M, Rivera Núñez, D., Obón de Castro, C. (1989). Improntas vegetales de adobes

\section{BIBLIOGRAFÍA}

procedentes de la casa A del yacimiento argárico en llanura de Rincón de Almendricos, Lorca, Murcia, en Crónica del XIX Congreso Arqueológico Nacional (Castellón, 1987) 1, Zaragoza, pp. 279291.

Baloi, M.D.L. (2001). Archaeology and mud wall decay in the Bowirba area: an ethnoarchaeological study. Pula: Botswana Journal of African Studies $15,1$.

Contreras Cortés, F. (2009).Losgruposargáricos de la Alta Andalucía: patrones de asentamiento y urbanismo. El poblado de Peñalosa (Baños de la Encina, Jaén), AnMurcia 25-26, pp. 49-76.

De Pedro Michó, M. J (1990). La Lloma de Betxí, Paterna: datos sobre técnicas de construcción en la Edad de Bronce, Archivo de Prehistoria levantina 20, pp. 327-350.

De Pedro Michó, M. J. (1998). La Lloma de Betxí (Paterna, Valencia). Un poblado de la Edad del Bronce, Valencia.

Fumanal García, M. P, Hernández Pérez, M. S., Ferrer García, C., Serna Gancedo, A., Batlle Sales, J., Martínez Gallego, J., Bordás Valls, V. (1996). Estudio geoarqueológico de Cabezo Redondo (Villena, Alicante): un yacimiento de la Edad del Bronce y sus condicionantes medioambientales, Cuaternario y Geomorfología 10 (3-4), pp. 5-20.

García Guardiola, J. (2004). Los Pedruscales: yacimiento de la Edad del Bronce junto a la rambla del Panadero (Villena, Alicante), en Hernández Alcaraz, L., Hernández Pérez, M. S. (eds.), La Edad del Bronce en tierras valencianas y zonas limítrofes, Alicante, pp. 347-350.

Guidoni, E. (1977). Arquitectura primitiva, Madrid.
Hernández Alcaraz, L., Pérez Amorós, L., Menargues Giménez, J. (2004). El poblado de Las Peñicas (Villena, Alicante). Excavaciones de José María Soler, en Hernández Alcaraz, L., Hernández Pérez, M. S. (ed.), La Edad del Bronce en tierras valencianas y zonas limítrofes, Alicante, pp. 351362.

Hernández Pérez, M. S. (2001). La Edad del Bronce en Alicante, en Hernández Pérez, M. S.,...Y acumularon tesoros. Mil años de historia en nuestras tierras, Alicante, pp. 201-217.

Hernández Pérez, M. S. (2012). El Cabezo Redondo (Villena, Alicante) y el Bronce Tardío en las tierras meridionales valencianas, en Rodríguez Marcos, J. A., Fernández Manzano, J. (coords.), Cogotas I: una cultura de la Edad del Bronce en la Península Ibérica: Homenaje a $M^{a}$ Dolores Fernández-Posse, Valladolid, pp. 111-146.

Hernández Pérez, M. S., García Atiénzar, G., Barciela González, V., Lillo Bernabeu, M., Martorell Briz,X.(2014).Cabezo Redondo(Villena,Alicante). Caracterización de "espacios domésticos" en un poblado del Bronce Tardío. Campañas de 2010 a 2012, en Olcina Doménech, M., Soler Díaz, J. A (eds.), II Jornadas de arqueología y patrimonio alicantino. Arqueología en Alicante en la primera década del siglo XXI, MARQ, Arqueología y Museos, Extra 1, pp. 215-221.

Jover Maestre, F. J., López Padilla, J. A. (2009). Más allá de los confines del Argar. Los inicios de la Edad del Bronce y la delimitación de las áreas culturales en el cuadrante suroriental de la Península Ibérica, 60 años después, en Hernández Pérez, M. S., Soler Díaz, J. A., López Padilla, J. A. (eds.), Los confines del Argar. Una cultura de la Edad del Bronce en Alicante, Alicante, pp. 268291. 
Jover Maestre, F. J., López Padilla, J. A. (2013). La producción textil durante la Edad del Bronce en el cuadrante suroriental de la Península ibérica: materias primas, productos, instrumentos $\mathrm{y}$ procesos de trabajo, Zephyrus LXXI, pp. 149-171.

Jover Maestre, F. J., Martínez Monleón, S. (2012). Excavaciones arqueológicas en el yacimiento de la Edad del Bronce de Polovar (Villena, Alicante), Memoria inédita, Conselleria de Cultura, Generalitat Valenciana.

Jover Maestre, F. J., López Padilla, J. A., GarcíaDonato Layrón, G. (2014). Radiocarbono y estadística Bayesiana: aportaciones a la cronología de la Edad del Bronce en el extremo oriental del sudeste de la península Ibérica, Saguntum 46, pp. 41-68.

Jover Maestre, F. J., López Padilla, J. A., Machado Yanes, M. C. (2001). La producción textil durante la Edad del Bronce: un conjunto de husos o bobinas de hilo del yacimiento de Terlinques (Villena, Alicante), Trabajos de Prehistoria 58, 1, pp. 171-186.

Jover Maestre, F. J., Martínez Monleón, S., Pastor Quiles, M., Poveda Hernández, E., López Padilla, J. A. (2016). Los asentamientos de pequeño tamaño de la Edad del Bronce en tierras valencianas: A propósito del Cabezo del Polovar (Villena, Alicante), Recerques del Museu d'Alcoi 25.

Machado Yanes, M. C., Jover Maestre, F. J, López Padilla, J. A. (2009). Antracología y paleoecología en el cuadrante suroriental de la península Ibérica: las aportaciones del yacimiento de la Edad del Bronce de Terlinques (Villena, Alicante), Trabajos de Prehistoria 66, 1, pp. 75-96.

Machado Yanes, M. C., Jover Maestre, F. J., López Padilla, J. A., Luján Navas, A. (2008). Arqueología, etnobotánica y campesinado: el uso de la madera en el asentamiento de Terlinques (Villena, Alicante), MARQ Arqueología y museos 3, pp. 9-32.

Mileto, C., Vegas, F., Cristini, V. (2012). Refuerzos y mejoras: variantes constructivas de la tapia en España, Actas del Congreso Iberoamericano de
Arquitectura y Construcción en tierra SIACOT 2012, Lima.

Oluwole Ogundele, S. (2005). Ethnoarchaeology of Domestic Space and Spatial Behaviour Among the Tiv and Ungwai of Central Nigeria, African Archaeological Review 22, 1, pp. 25-54.

Pastor Quiles, M. (2014). Cabezo Pardo. Contribución a las formas constructivas de un hábitat argárico a partir del estudio de los elementos de barro, en LÓPEZ PADILLA, J. A. (coord.), Cabezo Pardo (San Isidro/ Granja de Rocamora, Alicante). Excavaciones arqueológicas en el yacimiento de la Edad del Bronce, Memorias Excavaciones Arqueológicas 6, Alicante, pp. 306321.

Reimer, P.J., Bard, E., Bayliss, A., Beck, J.W., Blackwell, P.G., Bronk Ramsey, C., Buck, C.E., Cheng, H., Edwards, R.L., Friedrich, M., Grootes, P.M., Guilderson, T.P., Haflidason, H., Hajdas, I., Hatté, C., Heaton, T.J., Hoffmann, D.L., Hogg, A.G., Hughen, K.A., Kaiser, K.F., Kromer, B., Manning, S.W., Niu, M., Reimer, R.W., Richards, D.A., Scott, E.M., Southon, J.R., Staff, R.A., Turney, C.S.M. Van der Plicht, J. (2013). IntCal13 and Marine13 Radiocarbon Age Calibration Curves 0-50,000 Years cal BP. Radiocarbon 55, 4, pp. 1869-1887.

Rivera Groennou, J. M. (2007). Aproximación a las formas constructivas en una comunidad de la Edad del Bronce: El poblado argárico de Peñalosa (Baños de la Encina, Jaén), Arqueología y territorio 4, pp. 5-21.

Soler García, J. M. (1987). Excavaciones arqueológicas en el Cabezo Redondo (VillenaAlicante), Alicante. 